\title{
Zwischen Platon, Ardaschir und Mohammed: Politische Philosophie in der
} islamischen Welt

\author{
Rudolph, Ulrich
}

Posted at the Zurich Open Repository and Archive, University of Zurich

ZORA URL: https://doi.org/10.5167/uzh-181564

Book Section

Published Version

Originally published at:

Rudolph, Ulrich (2019). Zwischen Platon, Ardaschir und Mohammed: Politische Philosophie in der islamischen Welt. In: Riedweg, Christoph. Philosophie für die Polis : Akten des 5. Kongresses der Gesellschaft für antike Philosophie 2016. Berlin: De Gruyter, 507-532. 


\section{Zwischen Platon, Ardaschir und Mohammed: Politische Philosophie in der islamischen Welt}

\section{Einleitung: der Islam als Religion und Staat?}

Der Islam wird heute in der Regel als eine politische Religion wahrgenommen. Das gilt nicht nur für seine Einschätzung durch außenstehende Beobachter und Kommentatoren, sondern auch für die Selbstwahrnehmung vieler Muslime. Sie artikuliert sich häufig in Aussagen und Begriffen, die eine enge Verzahnung, wenn nicht die Identität von religiöser und politischer Sphäre vermuten lassen. Dazu zählen das Postulat, die Scharia sei auf alle Bereiche der Gesellschaft anzuwenden; ${ }^{1}$ die oft wiederholte Formel „Der Islam ist [sc. beides:] Religion und Staat“ (al-islām dīn wa-daula), die auch in der Variante „Der Islam ist [sc. beides:] Religion und [sc. diesseitige] Welt“ (al-islām dīn wa-dunyā) auftritt. ${ }^{2}$ Ganz zu schweigen davon, dass seit einiger Zeit ein Gebilde, das sich als „Islamischer Staat“ bezeichnen lässt, in apokalyptischer Zuspitzung die Verbindung von religiöser Propaganda und Gewaltherrschaft zelebriert. ${ }^{3}$

All das sind irritierende Befunde, die scheinbar alternativlos in eine bestimmte Richtung weisen. Sie haben die Felder „Islam“ und „Politik“ im öffentlichen Diskurs weitgehend besetzt und scheinen in ihrem Anspruch, Islamizität zu repräsentieren, konkurrenzlos zu sein. Allerdings: So auffällig solche Modelle derzeit auch sind - sie können doch nicht für sich in Anspruch nehmen, die einzige oder auch nur die wichtigste Form des politischen Denkens in der islamischen Welt darzustellen. Denn Alternativen zu dieser exzessiven Form der

1 Dazu allgemein Akhavi 2011, 789-790; besonders prominente Beispiele für diese weit verbreitete These sind (a) Ḥasan al-Bannā' (gest. 1949), der Begründer der Muslimbruderschaft (zu ihm Krämer 2010), sowie (b) Sayyid Quṭb (gest. 1966), der einflussreichste Vordenker der Strömung, die heute allgemein als Islamismus bezeichnet wird (zu ihm Damir-Geilsdorf 2003; Khatab 2006; Calvert 2010).

2 Akhavi 2011, 789; vgl. Damir-Geilsdorf 2003, 61-78; Khatab 2006, 7-15; Krämer 2010, 106107, 112-116; für weitere Überlegungen zu diesem Slogan s. unten Anm. 57.

3 Die Literatur, die in den letzten Jahren zum sogenannten „Islamischen Staat“ publiziert wurde, ist ausgesprochen umfangreich, aber nicht immer verlässlich. Als Einführung in die Thematik eignet sich Günther 2014; eine Analyse wichtiger propagandistischer Texte gibt Sievert 2015. 
politischen Theologie hat es immer gegeben. Sie bestehen heute, insofern andere muslimische Stimmen der Gegenwart, wenn auch weniger lautstark, die strikte Trennung von Religion und Politik befürworten. ${ }^{4}$ Und sie bestanden in früheren Zeiten, als sich die islamistischen Strömungen des 20. und 21. Jahrhunderts noch gar nicht formiert hatten.

Man könnte folglich an dieser Stelle darauf verweisen, dass es nicht einen Islam gibt, sondern eine Vielfalt von Meinungen und Strömungen, die zum Islam gehören. Damit wären wir bei einer Argumentation angekommen, die uns in jüngster Zeit häufig begegnet, zumal sie nicht nur in der wissenschaftlichen Literatur, sondern auch in den verschiedensten medialen Foren bis hin zu Talkshows verbreitet wird. Ganz so einfach sollten wir es uns in diesem Kontext aber nicht machen. Denn der Verweis auf die Pluralität islamischer Konzepte ist zwar korrekt. ${ }^{5}$ Aber er genügt nicht, wenn es darum geht, die primären Konstituenten des politischen Denkens im Islam auszumachen, d. h. festzustellen, von welchen Grundlagen es ausgegangen ist und in welchen Formen es sich in den ersten Jahrhunderten des Islams realisiert hat.

Das auszuloten ist das Anliegen dieses Beitrags. Er konzentriert sich auf die Frühzeit der islamischen Geschichte und dort wieder auf die Anfänge des politischen Denkens. Denn genau da liegen ja die Grundlagen, auf die sich islamistische Gruppen von heute in ihrer Argumentation so gerne beziehen, wenn sie das Bild eines ,ursprünglichen', angeblich ,authentischen' Gemeinwesens von

4 Akhavi 2011, 790-791; interessante Beispiele dafür finden sich bei Meddeb 2007; Amirpur 2009; 2013; Kadivar 2017; vgl. auch den unkonventionellen theoretischen Ansatz, der von Sing 2007 analysiert wird.

5 Der wichtigste wissenschaftliche Beitrag der letzten Jahre, der in diesem Sinne argumentiert, stammt von Bauer 2011. Er vertritt die These, die Kultur des vormodernen Islams (bis ca. 1800) sei wesentlich von „Ambiguität“ geprägt gewesen. Das habe sich in der prinzipiellen Bereitschaft der Muslime manifestiert, divergierende Diskurse und unterschiedliche Möglichkeiten der Interpretation nebeneinander zuzulassen, was am besten als „Ambiguitätstoleranz“ (13 u.ö.) zu beschreiben sei. Bauer kann für diesen Befund eindrückliche Belege aus der Literatur, Poesie wie Prosa, vorweisen. Sobald er jedoch auf wissenschaftliche Diskurse (Philosophie, Theologie, Wissenschaften von der Natur, Logik usw.) zu sprechen kommt, wird seine Argumentation rhapsodisch und läuft Gefahr, die eigentlichen, zumeist auf Disambiguierung zielenden Intentionen der besprochenen Autoren zu verkennen. Seine Ausführungen zum politischen Diskurs der Muslime (315-343) sind trotzdem interessant, denn sie verbinden Beobachtungen zur literarischen Tradition mit solchen zur wissenschaftlichen Literatur. Einzelne Überlegungen daraus werden hier später noch zur Sprache kommen, wobei meinerseits vorausgesetzt wird, dass es stets eine Pluralität von politischen Konzepten in der islamischen Welt gegeben hat, ohne dass diese jedoch dem generalisierenden Deutungsmuster der „Ambiguität(stoleranz)“ unterworfen werden sollte. 
Muslimen beschwören, das ideal gewesen sei und zu dem es zurückzukehren gelte. Wir werden uns also mit den Anfängen der islamischen Gesellschaft befassen. Mit anderen Worten: Unser Ausgangspunkt ist die Spätantike, an deren Ende im Nahen Osten gewaltige politische und soziale Umwälzungen stattfanden und eine Vielzahl von intellektuellen Strömungen aufeinander trafen. Sie zu erforschen ist ein gemeinsames Anliegen der Fächer, die sich bei dieser Tagung begegnet sind, der Philosophie, der Altertumswissenschaften und der Islamwissenschaft, und so mag diese kurze Erörterung ein Beleg dafür sein, dass die Zusammenarbeit zwischen diesen drei Disziplinen nicht nur historisch interessante, sondern auch für die Gegenwart relevante Ergebnisse zeitigen kann.

\section{Drei Kontexte früher islamischer Herrschaft}

Beginnen wir mit einem Blick auf die Anfänge des muslimischen Gemeinwesens. Sie lagen in Medina, der „Stadt des Propheten“ (madinat an-nabī), wo Mohammed zehn Jahre lang, von seiner Auswanderung aus Mekka im Jahr 622 bis zu seinem Tod im Jahr 632, wirkte. Dabei gelang es ihm, seine Anhängerschaft, die zuvor kaum organisiert war, zu stabilisieren und ein Gemeinwesen aufzubauen, das strukturiert war und unter seiner Autorität und Leitung stand. ${ }^{6}$ Medina sollte allerdings nicht lange der zentrale Schauplatz der islamischen Geschichte bleiben. Schon zehn Jahre nach dem Tod des Propheten war es seinen Nachfolgern gelungen, entscheidende militärische Siege über die Byzantiner und die Sassaniden zu erringen. Das führte sehr schnell dazu, dass sich das Zentrum des politischen Geschehens nach Norden verlagerte. Zunächst nach Damaskus, in ehemals byzantinisches Gebiet, wo die Omayyadenkalifen ab 661 regierten. Später nach Bagdad, das 762 von den Abbasidenkalifen im ehemaligen sassanidischen Kernland gegründet wurde. Die neue Kapitale, unweit von Babylon und Ktesiphon gelegen, demonstrierte endgültig den imperialen Anspruch, der von den neuen Herren und ihrer Politik erhoben wurde: Sie wollten nicht nur eine erfolgreiche Herrschaft von Arabern etablieren, sondern über alle

6 Von den zahlreichen Monographien über das Leben Mohammeds bzw. über die Quellenaussagen, die uns zu seinem Leben vorliegen, seien hier nur Bobzin 2000 und Schöller 2008 genannt. Zur Einführung in die schwierige Problematik der Leben-Mohammed-Forschung vgl. Rudolph/Uehlinger 2014 sowie die Beiträge von Fred M. Donner, Tilman Nagel, Gregor Schoeler sowie Andreas Görke und Harald Motzki, die in Band 68 (2014) der Asiatischen Studien erschienen sind. 
Muslime, gleich welcher Provenienz, regieren und zugleich Nachfolger der beiden antiken Großreiche - Ostrom und Iran - sein. ${ }^{7}$

Das politische Denken und Handeln der frühen Muslime hatte seine Wurzeln demnach nicht nur in Arabien. Es entfaltete sich vielmehr auf einer ungewöhnlich breiten Grundlage, zu der neben der altarabischen Tradition auch das byzantinisch-griechische sowie das sassanidisch-iranische Erbe gehörten. Das wird im Titel dieses Beitrags mit einem ungewöhnlichen Triumvirat angedeutet: Platon steht hier für das griechische Erbe, Ardaschir, der Gründer und legendäre Ahnherr der Sassaniden, für das iranische, Mohammed für das arabische bzw. das arabisch-islamische. Dabei ist allerdings zu bedenken, dass diese Traditionen von Anfang interagiert haben und nicht je für sich, sondern gemeinsam den Horizont repräsentieren, vor dem sich das politische Denken in der islamischen Welt entwickelt hat. Wie das geschehen ist, soll im folgenden in zwei Schritten dargelegt werden. Der erste, etwas kürzere besteht darin, dass wir uns die materiellen Grundlagen dieser drei Überlieferungen klar legen, $d . h$. festhalten, durch welche Texte und Textgattungen sie in den ersten Jahrhunderten des Islams greifbar waren. Der zweite, ausführlichere Schritt löst sich dann vom überlieferten Material und nimmt die Diskussion in den Blick, die sich in der islamischen Gesellschaft selbst entwickelte. $\mathrm{Zu}$ diesem Zweck werden wir drei Schriften aus dem 10. und 11. Jahrhundert betrachten, die jeweils eine der Überlieferungen (die arabisch-islamische, die griechische oder die iranische) aufgreifen und so innovativ auf die Fragen ihrer Zeit anwenden, dass sie selbst $\mathrm{zu}$ Klassikern der politischen Literatur in der islamischen Welt geworden sind.

\section{Drei Traditionen politischen Denkens: arabisch- islamisch, griechisch, iranisch}

Zunächst zum ersten Schritt, der Frage nach den materiellen Grundlagen der Überlieferung. Sie lässt sich recht gut für alle drei Traditionen beantworten, wobei unser Kenntnisstand allerdings jeweils unterschiedlich ist. Was das arabisch-islamische Erbe betrifft, das unmittelbar mit der Person Mohammeds verbunden war, so wird es vor allem in drei Zeugnissen greifbar. Das erste ist der Koran, das Gründungsdokument des Islams und zugleich der früheste Text, der uns Auskunft über das Wirken des Propheten gibt. Sein Thema ist natürlich

7 Die wichtigsten Daten und Ereignisse sind zusammengestellt bei Endreß 1982, 140-144. 193197. 
die Religion, denn sein Ziel lautet, das Verhältnis des Menschen zu Gott und zum Jenseits neu auszurichten. Aber der Koran enthält auch eine Reihe von Aussagen, die sich auf das Diesseits beziehen und erkennen lassen, dass der islamische Offenbarung in einem sozialen und politischen Kontext erfolgt ist. Dazu zählen juristische Bestimmungen, mit denen Verhältnisse zwischen den Menschen geregelt werden; ${ }^{8}$ historische Anspielungen auf Ereignisse aus der Zeit Mohammeds, aus denen hervorgeht, dass man in Arabien sehr wohl über die große Politik und speziell über Vorgänge in Byzanz und in Iran informiert war; ${ }^{9}$ schließlich drei Konzepte, die ebenfalls religiös motiviert waren, aber später auch im Rahmen des politischen Denkens Anwendung fanden: (1) das Konzept der umma, also einer Gemeinschaft von Gläubigen, die sich im Sinne des göttlichen Heilsplan konstituiert hat - übrigens ein Terminus, der aus dem Akkadischen, dem Hebräischen oder dem Aramäischen übernommen worden sein dürfte; (2) die Idee, dass der Mensch von Gott als halïfa, das heißt als „Stellvertreter“ bzw. als „Nachfolger“ in der Schöpfung eingesetzt worden sei; und (3) das Konzept des ğihād, das meist als „Anstrengung auf dem Wege Gottes“ (ǧihād fì sabīli llāh) konkretisiert wurde und durchaus als Einsatz im Kampf verstanden werden kann. ${ }^{10}$

Das zweite wichtige Dokument aus Mohammeds Lebenszeit sind Verträge, die er als Leiter des muslimischen Gemeinwesens geschlossen hat, soweit sie uns erhalten sind. Sie beleuchten einzelne Aspekte seines Selbstverständnisses und seiner Sicht auf die Muslime und deren Vertragspartner. Das gilt insbesondere für die sogenannte „Gemeindeordnung von Medina“, die offenbar kurz nach der Hidschra verfasst wurde und dazu diente, die Rechte der verschiedenen muslimischen Gruppen und der jüdischen Stämme, die in der Stadt ansässig waren, $\mathrm{zu}$ regeln. ${ }^{11}$

Als drittes ist hier noch das Hadith, die Überlieferung von Aussprüchen und Taten Mohammeds zu nennen. Es enthält unter anderem ethische Maximen, politische Ratschläge und juristische Entscheidungen und sollte insgesamt eine „gute Gewohnheit“ (sunna) etablieren, die alle Muslime auf das Vorbild Mohammeds verpflichtete. Zugleich stellt das Hadith ein Bindeglied zu älteren

8 Nagel 1983, 299-325 („Das göttliche Gesetz“).

9 Interessant ist in diesem Zusammenhang vor allem Sure 30, die den Titel ar-Rūm (Die [Ost]Römer, d. h. Die Byzantiner) trägt. Zum Koran als Geschichtsquelle vgl. Nagel 1983, 86-118. $10 \mathrm{Zu}$ politischen Vorstellungen im Koran s. Denny 2001 und vor allem Böwering 2013b. Die Konzepte umma, halīfa und ğihād werden von Böwering 2013b, 453-454 erläutert; zur Etymologie des Wortes umma Denny 2001, 371 mit weiteren Literaturhinweisen; zu halifa vgl. auch unten Anm. 58.

11 Watt 1968, 4-6; Denny 1977; Emon 2001; Lecker 2013 mit weiteren Literaturhinweisen. 
Traditionen dar, denn es war schon vor Mohammeds Zeit in Arabien üblich, die „guten Gewohnheiten“ hervorragender Personen zu überliefern und als Modell für spätere Generationen zu präsentieren. Deswegen kann es auch kaum verwundern, dass die Hadithsammlungen Material erhalten, das aus verschiedenen älteren und jüngeren Kontexten stammen dürfte. ${ }^{12}$

Vergleichbares gilt für den zweiten großen Strang an Überlieferungen, der uns hier interessiert, d. h. das griechische Erbe. Er bildete ebenfalls kein homogenes Textkorpus, sondern eine Sammlung von Elementen, in denen sich verschiedene Stadien und Formen des antiken politischen Denkens - von Hellas über Rom und Byzanz bis hin zu den spätantiken orientalischen Christen widerspiegelten. Greifbar wird dieses Erbe zum ersten Mal in der späten Omayyadenzeit, also kurz vor der Mitte des 8. Jahrhunderts. Damals wurden mehrere pseudepigraphische Briefe, die angeblich von Aristoteles an Alexander adressiert waren, vermutlich aus dem Griechischen ins Arabische übersetzt. Damit sollte eine ganze Serie von griechisch inspirierter Weisheitsliteratur ihren Anfang nehmen. Denn von nun an tauchten immer wieder Schriften auf, die antiken Autoritäten zugeschrieben wurden und Ratschläge für das Leben als Individuum und in der Gemeinschaft enthielten. Sie gehörten verschiedenen Textgattungen an, denn es konnten Doxographien sein, Gnomologien, Episteln oder Fürstenspiegel. Sie konnten direkt aus dem Griechischen übersetzt sein oder auf Arabisch verfasst worden sein, wobei dann meistens griechische Vorlagen eine große Rolle spielten. In jedem Falle aber handelte es sich um populäre Literatur, die viele Leser fand und wesentlich dazu beitrug, dass antike Vorstellungen über Ethik und Politik weite Verbreitung fanden. ${ }^{13}$

Neben dieser Literatur, oder man könnte auch sagen: oberhalb von ihr gab es indes noch einen zweiten Überlieferungsstrang, auf dem griechisches politisches Denken in der islamischen Welt bekannt wurde. Er betraf Werke der Schulphilosophie, die neben solchen der Medizin, Mathematik, Astronomie und anderer Wissenschaften zwei Jahrhunderte lang Gegenstand des großen griechisch-arabischen Übersetzungsprozesses waren. ${ }^{14}$ In seinem Verlauf wurden

12 Allgemein zu Entstehung und Problematik des Hadith Juynboll 1983; Motzki 2004; 2014; interessante Belege für die Übernahme älteren Materials in Hadithtexten bieten noch immer die Arbeiten von Goldziher, z.B. 1902 und 1908; zur Entwicklung des sunna-Konzepts von einer allgemeinen, tradierten Norm („mos maiorum“) zu einer speziellen, ganz auf Mohammed fokussierten Sammlung von Regeln s. Crone/Hinds 1986, 58-96.

13 Einen Überblick über dieses Schrifttum gibt Gutas 2012b mit zahlreichen weiteren Literaturhinweisen.

14 Zum Übersetzungsprozess, seinen politischen und sozialen Hintergründen und seiner weitreichenden Bedeutung s. Gutas 1998. 
vergleichsweise wenige politische Traktate ins Arabische übersetzt, was vielleicht ein Beleg dafür ist, dass die griechische Philosophie auf diesem Gebiet im Unterschied zu Logik, Physik oder Metaphysik - nur eine von mehreren möglichen Inspirationsquellen bildete. Gleichwohl sollte der Anteil der praktischen Philosophie am griechisch-arabischen Rezeptionsprozess nicht vernachlässigt werden. Denn die arabischen Leser lernten im 9. Jahrhundert immerhin die Nikomachische Ethik und einige Teile der Politik des Aristoteles kennen. Darüber hinaus rezipierten sie Platons Politeia, die Nomoi und den Politikos, wenn auch nicht im platonischen Original, so doch in den ausführlichen Kompendien, die Galen davon erstellt hatte. ${ }^{15}$

Dass es gleichwohl bei dieser partiellen Rezeption von Texten blieb, dürfte damit zu tun haben, dass die Araber parallel zum griechischen Erbe das politische Denken aus Iran kennenlernten. Es erlebte seinen Aufschwung mit dem Wechsel von den omayyadischen zu den abbasidischen Kalifen (um 750). Diese gründeten, wie erwähnt, 762 Bagdad als neue Hauptstadt und knüpften damit sehr bewusst nicht nur an Byzanz, sondern auch an die imperiale Tradition der Sassaniden an. ${ }^{16}$ Entsprechend groß ist der Umfang der politischen Literatur, die in der frühen Abbasidenzeit aus dem Mittelpersischen ins Arabische übersetzt wurde. ${ }^{17}$ Dazu gehören klassische iranische Ratgeberschriften wie Der Brief an Tansar, ${ }^{18}$ das Buch der Krone (Kitāb at-Tāğ), ${ }^{19}$ das zu Unrecht al-Ǧāhìiz (gest. 869) zugeschrieben wurde, und vor allem das berühmte Testament des Ardaschir ('Ahd Ardašir). ${ }^{20}$ Es behandelt der Reihe nach zentrale Fragen der politischen Philosophie wie die Aufgaben des Herrschers, seine Beziehung zu den Untertanen, die Regierungskunst, die Kriegsführung, die Beziehungen zu feindlichen Staaten, Gerechtigkeit, die Legitimität von Herrschaft und die richtige Regelung der Nachfolge. Neben den Übersetzungen kam es zu dem Phänomen, dass Originalschriften auf Arabisch entstanden, die weitgehend auf älterem,

15 Eine Liste aller griechischen philosophischen Texte, die ins Arabische übersetzt wurden, findet sich bei Gutas 2012a, 79-87; zur Nikomachischen Ethik s. Ullmann 2012; zur Überlieferung der Politik des Aristoteles Pines 1986; Brague 1993; zur Überlieferung der platonischen Dialoge De Smet 2011.

16 Gutas 2012a, 58-61.

17 Für einen Überblick über dieses Textkorpus s. Gutas 2012b, 465-468. 474 sowie Haghighat 2015; vgl. auch Zakeri 2015.

18 Engl. Übersetzung von Boyce 1968 (s. unten Tansar im Literaturverzeichnis).

19 Edition der arab. Fassung von Zaki 1914; franz. Übersetzung von Pellat 1954; zum Text Grignaschi 1966, 4-5.

20 Edition der arab. Fassung von 'Abbās 1967; zum Text Grignaschi 1966, 2-3. 8-11; vgl. auch Haghighat 2015, 86; Zakeri, 2015, 181-183. 
iranischem Gedankengut basierten. Zwei von ihnen wurden gleich zu Beginn der Abbasidendynastie von einem Wesir namens Ibn al-Muqaffa' (gest. 756) verfasst. ${ }^{21}$ Eine dieser Schriften trägt den Titel Das große Buch des richtigen Verhaltens (Kitāb al-Adab al-kabirr) und verbindet stilistische Eleganz mit einer Eloge auf das alte Iran und einer Sammlung von ethischen und politischen Maximen.22 Die andere heißt Epistel über das Gefolge [sc. des Kalifen] (Risāla fi șșahāba) und ist ein scharfsinniger politischer Ratgeber, der ganz im Sinne der persischen Tradition argumentiert, alleine der Herrscher dürfe höchste Autorität und die vollkommene Verfügungsgewalt in Fragen des Staates und der Religionsausübung besitzen. ${ }^{23}$

Alle drei gerade erwähnten Traditionen fanden jeweils eine Fortsetzung und entwickelten sich kontinuierlich weiter. Dabei kam es zu zahlreichen Berührungen zwischen ihnen, die zu den verschiedensten Formen der Aneignung, Kombination und Neubewertung von Motiven führten. Ein beredtes Beispiel dafür ist der berühmte ps.-aristotelische Fürstenspiegel Sirr al-asrār, Das Geheimnis der Geheimnisse, der bei uns vor allem unter dem lateinischen Titel Secretum secretorum bekannt ist. Er entstand im 10. Jahrhundert auf Arabisch auf der Basis verschiedener hier schon erwähnter Quellen und sollte sowohl in der islamischen Welt als auch in Europa zu einer der meistgelesenen politischen Schriften des Mittelalters und der frühen Neuzeit werden..$^{24}$

Als dieser Text geschrieben wurde, war es allerdings kaum mehr üblich, politischen Ratschlägen dadurch Gewicht zu geben, dass man sie im Namen antiker Autoritäten verkündete. Die Muslime hatten nämlich inzwischen das verfügbare antike Erbe adaptiert und waren längst dabei, im Diskurs über das Gemeinwesen mit eigener Stimme aufzutreten. Wie sich diese Stimmen artikulierten, soll im folgenden, wie erwähnt, an drei exemplarischen Schriften aus dem 10. und 11. Jahrhundert gezeigt werden. Sie schließen jeweils an eine der genannten Überlieferungsstränge an, weshalb es sich eigentlich lohnen würde, alle drei einer genaueren Betrachtung zu unterziehen. Mit Blick auf den thematischen Fokus dieser Tagung werden jedoch zwei der Schriften hier nur kurz

21 Zu Person und Wirken s. van Ess 1991-1997, II (1992) 22-29; Latham 1997; Hamori 2013.

22 Der arab. Text liegt in mehreren Druckausgaben vor, wurde bislang aber weder genauer untersucht noch in eine europäische Sprache übersetzt; für einzelne Beobachtungen s. Lambton 1981, 54; Horst 1987, 210; Haghighat 2015, 87, 91.

23 Edition und franz. Übersetzung des Textes von Pellat 1976; Inhaltsangabe bei Goitein 1949; zur Interpretation Lambton 1981, 50-54; Nagel 1981, I 148-153. 161-183.

24 Editionen des arab. Textes von Badawi 1954 und al-A'war 1986; ausführliche Untersuchungen zum Werk und seiner Wirkungsgeschichte bei Ryan/Schmitt 1982 sowie Forster 2006. 
behandelt werden, während der dritte Text, der vor allem das griechische Erbe aufgreift, etwas ausführlicher zur Sprache kommen wird.

\section{Neue Konzeptualisierungen: drei Klassiker der politischen Literatur}

Die Tradition, die wir hier Medina bzw. den arabischen Anfängen des Islams zugeordnet haben, fand einen ihrer auffälligsten Repräsentanten in Abū l-Ḥasan al-Māwardī (974-1058). Er stammte aus Basra, verbrachte aber die meiste Zeit seines Lebens in Bagdad, wo er als hochgeschätzter Jurist und Diplomat am Kalifenhof angestellt war. ${ }^{25}$ Einem Kalifenhof übrigens, der zwar nominell noch immer die höchste Autorität für alle Muslime bildete. Tatsächlich aber hatte der Abbasidenkalif seine Unabhängigkeit längst eingebüßt und stand „unter dem Schutz“, wie es euphemistisch hieß, eines militärisch und politisch überlegenen Herrschers, der seinerseits den Titel „Emir“ oder „Sultan“ trug. ${ }^{26}$ Nachdem alMāwardī mehrere Jahrzehnte lang am Hof gewirkt hatte, legte er seine Beobachtungen und Überlegungen schriftlich nieder. So entstand ein Werk mit dem Titel Die Bestimmungen der Herrschaft (al-Aḥkām as-sulțāniyya), das systematisch die Aufgaben, Rechte und Pflichten der verschiedenen Regierungsämter und Verwaltungspositionen untersucht und dabei vor allem juristische Festlegungen mit einigen politischen Erwägungen verbindet. ${ }^{27}$

Die wichtigsten Themen des Buches sind folgende: die rechtlichen Grundlagen des Kalifats; die Pflichten des Kalifen; die Einsetzung von Wesiren, Generälen und Gouverneuren; die Rechtsprechung; die Behörde für Beschwerden gegen Ungerechtigkeit und Machtmissbrauch; die Organisation der rituellen Gebete und der Pilgerfahrt nach Mekka; die Steuerverwaltung; die Verteilung von Kriegsbeute und Landbesitz sowie die Aufsicht über den Markt und die Geschäftsabschlüsse. Die Bestimmungen der Herrschaft sind also in erster Linie ein normativer Text. Sein Hauptanliegen besteht darin, Regeln für die Leitung und Verwaltung des islamischen Gemeinwesens festzulegen. Dagegen enthält

25 Zu Māwardī's Leben und Wirken allgemein Akpinar 2013; vgl. Lambton 1981, 83-84; Nagel 1981, I 345-348.

26 Vgl. Endreß 1982, 145-149. 202-205 zum Emirat der Būyiden (10.-11. Jh.) sowie zum Sultanat der Seldschuken (ab der Mitte des 11. Jahrhunderts.).

27 Das Werk liegt in verschiedenen arabischen Druckausgaben vor, eine kritische Textedition fehlt jedoch bislang; franz. Übersetzung von Fagnan 1915; engl. Übersetzungen von Wahba 1996 und Yate 2005. 
er keinerlei theoretische Reflexion über das Wesen der islamischen Herrschaft; auch Äußerungen über deren ursprüngliche und möglicherweise ideale Verwirklichung zur Zeit des Propheten Mohammed findet man in dem Buch nirgends. ${ }^{28}$ Im Gegenteil: Al-Māwardī ist kein die Vergangenheit verklärender Idealist. Er plädiert eher dafür, juristische Normen anzupassen und pragmatisch anzuwenden. Das wird sehr deutlich, wenn er auf die aktuelle Situation des Kalifats zu sprechen kommt. Wie erwähnt, stand es damit zu seiner Zeit nicht gerade zum Besten, weil die Abbasiden längst ihre Hoheit verloren hatten und unter die Schutzherrschaft selbsternannter Emire und Sultane geraten waren. Genau dieses Skandalon akzeptiert der Jurist al-Māwardī allerdings. Denn er schreibt an einer berühmt gewordenen Stelle, dass eine Herrschaft, die durch Usurpation (istila $\vec{a}^{\prime}$ ) zustandegekommen sei, unter bestimmten Voraussetzungen durchaus legal sei und anerkannt werden müse. ${ }^{29}$ Das beweist einen starken Realitätssinn, zeigt aber auch die Flexibilität, mit der Bestimmungen des islamischen Rechts von ihm (und anderen Autoren) gehandhabt wurden. Selbst das Kalifat, also die Rechtsnachfolge des Propheten Mohammed, war in den Augen des berühmtesten sunnitischen Juristen der Frühzeit nichts Sakrosanktes, sondern konnte, wenn nötig, den historischen und politischen Umständen angepasst werden.

Ähnlich pragmatisch argumentiert die Schrift, die hier als Beispiel für das politische Denken in iranischer Tradition angeführt werden soll. Sie stammt ebenfalls aus dem 11. Jahrhundert, bewertet die Ereignisse dieser Zeit aber aus einer anderen Perspektive. Ihr Autor, der hochgebildete Wesir Niẓām al-Mulk (1018-1092), stand nämlich in Diensten der Seldschukensultane, also eben jenes Herrscherhauses, das zu seiner Zeit Bagdad besetzt hielt und sich zum Schutzherrn des abbasidischen Kalifen aufgeschwungen hatte. ${ }^{30}$

Sein Text ist auf (Neu)Persisch geschrieben und trägt den Titel Das Buch der Regierungskunst (Siyāsatnāma) bzw. Die [sc. richtigen] Lebensweisen der Könige

28 Zur Analyse des Werks Rosenthal 1958, 27-37; Little 1974; Lambton 1981, 83-102; Nagel 1981, I 348-369; Hamid 2001; Crone 2005, 222-233.

29 Das „Imamat durch Usurpation“ ist zum bekanntesten Konzept Māwardī’s geworden und wird in der Fachliteratur einhellig als sein wichtigster Beitrag zur Diskussion über legitime Herrschaftsformen angesehen; s. Little 1974, 236; Lambton 1981, 98-99; Nagel 1981, I 362-366; Hamid 2001, 225-228; Crone 2005, 233; vgl. auch Rosenthal 1958, 45-46, der sich in diesem Zusammenhang auf einen Nachfolger Māwardī’s namens Ibn Ǧamā'a (gest. 1333) bezieht.

30 Zu Nizāām al-Mulk’s Leben und Wirken allgemein Yavari 2013; vgl. Nagel 1981, I 425-426; Lambton 1984, 3-4. 
(Siyar al-mulūk). ${ }^{31}$ Dabei handelt es sich um einen elaborierten Fürstenspiegel, der in vieler Hinsicht an ältere iranische Ratgeber wie das Testament des Ardaschir, aber auch an das ps.-aristotelische Secretum secretorum anknüpft. Zu den Themen, denen Niz̄ām al-Mulk besondere Aufmerksamkeit schenkt, gehören die Einsetzung und die Aufgaben eines Herrschers, seine Gerechtigkeit, seine Kontrolle über sämtliche Ämter, die Organisation des Militärs und vor allem des Nachrichtendienstes, die Beratung mit Gelehrten, Regeln für das Hofzeremoniell, das Finanzwesen, Belohnung von Verdiensten, Mitgefühl mit Bedürftigen sowie - was besonders ausführlich thematisiert wird - die Bewahrung der richtigen Religion einschließlich der Abwehr häretischer Gruppierungen. All das kennt man im wesentlichen aus älteren Fürstenspiegeln. Selbst der Rat, die Angelegenheiten der Religion sehr genau und sehr streng $\mathrm{zu}$ beaufsichtigen, ist nicht neu, sondern steht in guter iranischer Tradition. ${ }^{32}$ Trotzdem erscheinen zwei Aussagen Nizāam al-Mulks als besonders bemerkenswert. Sie zeigen einmal mehr, wie flexibel und anpassungsfähig das politische Denken im frühen Islam artikuliert worden ist.

Eine Aussage betrifft die Frage, wer der oberste Souverän im Staat sei und auf welchen Grundlagen seine Herrschaft beruhe. Sie war im islamischen Recht eigentlich präzise geregelt, denn es ging dabei normalerweise um das Kalifenamt, also die Nachfolge des Propheten, dessen solitäre Stellung trotz aller Pragmatik auch von al-Māwardī nicht angetastet wurde. Ganz anders Nizāàm alMulk. Für ihn beruht Herrschaft darauf, dass „Gott, der Erhabene, in jeder Epoche eine Person aus der Mitte der Menschen auswählt, mit den Vorzügen eines Herrschers auszeichnet und mit dem Wohl der [sc. ganzen] Welt verbindet [...].“33 Mit anderen Worten: Die Herrschaft ist unmittelbar von Gott gewollt und wird nicht dadurch legitimiert, dass sie in der Nachfolge des Propheten steht. Der Herrscher muss also weder Araber sein noch aus dem mekkanischen Stamm der Quraisch geschweige denn aus der Familie Mohammeds stammen. Im Gegenteil: Er kann - wie die Selschukensultane, denen Niẓām al-Mulk diente aus Zentralasien kommen und erst jüngst in islamisches Gebiet eingewandert sein. Trotzdem sind die Seldschuken, wie unser Wesir betont, zu Recht Herr-

31 In der handschriftlichen Überlieferung ist der Titel Siyar al-mulūk häufiger belegt, aber das Werk ist heutzutage allgemein als Siyāsatnāma bekannt. Der persische Text ist mehrfach gedruckt, aber niemals kritisch ediert worden; franz. Übersetzung von Schefer 1893; engl. Übersetzung von Darke 1960; dt. Übersetzung von Schabinger von Schowingen 1960; zur Diskussion über die Autorschaft s. Lambton 1984, 3 mit Anm. 1.

32 Zur Analyse des Werks Rosenthal 1958, 81-83; Nagel 1981, II 83-92; Lambton 1984, 4-17.

33 Siyāsatnāma, Kap. 1, Anfang; franz. Übersetzung 5; engl. Übersetzung 9; dt. Übersetzung 160. 
scher über große Teile der Welt geworden. Denn ihnen gelang es, so die interessante Begründung, das glorreiche Iran zu erobern und mit seinem alten Rivalen, den Türken, zu versöhnen. ${ }^{34}$

Aus dieser Perspektive ergibt sich von selbst der zweite Punkt, der im Siyāsatnāma auffällt. Er betrifft die Frage, welche früheren Herrscher eigentlich herausragend waren und künftigen Generationen als Vorbilder dienen können. Sie wird von Niẓām al-Mulk mit einer Auflistung von Namen beantwortet, die ziemlich lang ist, aber keinerlei Hinweise auf Mohammed bzw. das ursprüngliche Gemeinwesen in Medina enthält. Die Liste lautet:

Sieh doch, wie groß der Name der weisen Herrscher in der Welt ist und welch große Taten sie vollbracht haben. Bis zur Auferstehung werden sie ihren Namen ruhmreich tragen, wie z.B. Faridūn, ${ }^{35}$ Alexander, ${ }^{36}$ Ardaschīr, ${ }^{37}$ Anūschirwān der Gerechte, ${ }^{38}$ 'Umar, der Fürst der Gläubigen ${ }^{39}$ - Gott sei ihm gnädig! -, 'Umar b. 'Abdu'l-'Azīz ${ }^{40}$ - Gott erleuchte seine Ruhestätte! -, Hārūn, ${ }^{41}$ Ma'mūn, ${ }^{42}$ Mu'taṣim, ${ }^{43}$ Ismā'īl b. Aḥmad der Sāmānide, ${ }^{44}$ Sultan Maḥmū $\mathrm{d}^{45}$ - Gottes Erbarmen über sie insgesamt! Taten und Werke eines jeden von ihnen sind

34 Siyāsatnāma, Kap. 1; franz. Übersetzung 7-8; engl. Übersetzung 10-11; dt. Übersetzung 162-163. Entscheidend an Niẓām al-Mulk's Argumentation ist an dieser Stelle der Hinweis, dass der von Gott auserwählte (Seldschuken-)Herrscher über beide Reiche, das iranische wie das türkische, regiert.

35 Ein mythischer König Irans, der im Königsbuch (Šāhnāma) von Abū l-Qāsim al-Firdausī (gest. um 1020) eine große Rolle spielt.

36 Alexander der Große.

37 Der Gründer der Sassanidendynastie.

38 Chosroes Anūširwān, der bedeutende Sassanidenherrscher des 6. Jahrhunderts (reg. 531578/9).

39 Der zweite Kalif (reg. 634-644), eine der maßgeblichen Herrscherfiguren der islamischen Frühzeit.

40 Omayyadenkalif (reg. 717-720), aus späterer islamischer Sicht der einzige fromme und vorbildliche Vertreter dieser Dynastie.

41 Der berühmte Abbasidenkalif Hārūn ar-Rašīd (reg. 786-809).

42 Abbasidenkalif (reg. 813-833).

43 Abbasidenkalif (reg. 833-842).

44 Reg. 892-907, Vertreter einer angesehenen iranischen Dynastie des 9. und 10. Jahrhunderts, die in Chorassan und Transoxanien regierte.

45 Mahmūd von Ġazna (reg. 998-1030), Gründer der Ġaznavidendynastie (mit Sitz im heutigen Afghanistan), die zu seiner Zeit weite Gebiete vom Oxus über Chorassan bis nach Nordindien beherrschte. Aus Sicht Niẓām al-Mulks war Maḥmūd schon deswegen ein bedeutender Regent, weil er - wie die Seldschukensultane - türkischer Abstammung war, aber ein Reich in Iran gründete, also die Herrschaft über beide ,Welten` verbinden konnte. 
augenscheinlich; Chroniken und Bücher wurden darüber geschrieben, und ihre Leser preisen und segnen jene Herrscher. ${ }^{46}$

Wir kommen zum dritten Text, der hier als Beispiel für das frühe politische Denken in der islamischen Welt dienen soll. Er wirft noch einmal einen ganz anderen Blick auf das Thema, dürfte uns aber in vielem vertrauter als die vorherigen sein, weil er sich stark an das griechische Erbe anlehnt. Der Text stammt von Abū Nașr al-Fārābī (um 870-950), dem bedeutendsten islamischen Philosophen des 10. Jahrhunderts. Er war weder als Staatsmann noch als politischer Ratgeber tätig, hinterließ aber eine Reihe von Schriften, die für die weitere Entwicklung der politischen Philosophie in der islamischen Welt grundlegend werden sollten. ${ }^{47}$

Eine von ihnen trägt den Titel Die Prinzipien der Ansichten der Bürger eines vortrefflichen Staates (Mabādi' ārä' ahl al-madīna al-fādilia)..$^{48}$ Sie beschreibt ausführlich, wie ein idealer Staat aufgebaut sein sollte, wobei al-Fārābī den Zustand eines Gemeinwesens ausdrücklich von den Qualitäten seines Herrschers, oder genauer gesagt: seines Gründers abhängig macht. Entsprechend lang ist die Liste der Eigenschaften, über die jener verfügen sollte. Sie enthält Tugenden wie Wahrheitsliebe, Gerechtigkeit und Entschlusskraft, die uns auch in den Fürstenspiegeln immer wieder begegnen. ${ }^{49} \mathrm{Im}$ Fokus seiner Überlegungen stehen jedoch die intellektuellen Fähigkeiten, die ein Staatsgründer besitzen sollte. Wie al-Fārābī betont, sollte sein Intellekt vollkommen sein und den Rang des erworbenen Intellekts, also der höchsten Erkenntnisstufe des Menschen, erreicht haben. Denn nur so kann er die Prinzipien des theoretischen und des praktischen Wissens ganz erfassen, was ihm die Möglichkeit gibt, die Ordnung des Gemeinwesens danach auszurichten. ${ }^{50}$ Kurz gesagt: Der erste Herrscher sollte Philosoph sein, denn nur ein Philosoph ist in der Lage, die Dinge zu erkennen, wie sie wirklich sind, und sein Wissen darüber mit demonstrativen Schlüssen zu beweisen. Wir sind also beim Philosophenkönig Platons ange-

46 Siyāsatnāma, Kap. 8; franz. Übersetzung 85; engl. Übersetzung 61; dt. Übersetzung 243-244 (danach hier zitiert).

47 Zu Fārābī’s Leben, Werken und Lehre ausführlich Rudolph 2012a mit zahlreichen Hinweisen auf die Primär- und Sekundärliteratur.

48 Kritische Edition des arab. Textes und engl. Übersetzung von Walzer 1985; dt. Übersetzung von Ferrari 2009; Ed. und franz. Übersetzung von Cherni 2011.

49 Fārābī, Mabādi' V, 15, § 12; engl. Übersetzung 247-249; dt. Übersetzung 91-93.

50 Fārābī, Mabādi' V, 15, § 8-11; engl. Übersetzung 241-247; dt. Übersetzung 89-91; zum Intellekt und seinen verschiedenen Stufen allgemein Mabādi' IV, 13; engl. Übersetzung 197211; dt. Übersetzung 69-74. 
kommen, der als Modell in al-Fārābī’s Überlegungen eine herausragende Rolle spielt. ${ }^{51}$

Allerdings geht al-Fārābī bei seiner Beschreibung des ersten Herrschers noch einen Schritt weiter. Sein Staatsgründer sollte nicht nur Philosoph sein, sondern auch die Gabe der Prophetie besitzen. Es genügt nämlich nicht, den Staat nach den Prinzipien der demonstrativen Erkenntnis einzurichten. Die meisten Bürger verstehen diesen Zugang zum Wissen gar nicht, sondern sind darauf angewiesen, dass ihnen die Wahrheit mit den Mitteln der Rhetorik und der Poetik, d. h. durch Gleichnisse, Symbole und Bilder nahegebracht wird. Hier kommt die Religion ins Spiel, denn ihre Aufgabe ist es, diese Form der Unterweisung zu leisten. Sie kann das tun, weil ihr Gründer - eben der Prophet - ein besonders starkes Vorstellungsvermögen besitzt, mit dessen Hilfe ihm die Wahrheit in Bildern und Symbolen vom Aktiven Intellekt geoffenbart wird. Es ist deswegen ideal, wenn der Gründer eines Staates sowohl Philosoph als auch Prophet ist, weil ihn dies in die Lage versetzt, beide Zugänge zur Wahrheit - den demonstrativen und den rhetorisch-poetischen - in seinem Gemeinwesen zu implementieren. Auf diese Weise können sämtliche Bürger Anteil an der Erkenntnis erhalten und ihre Vollkommenheit (kamāl) erlangen, was ihnen das Glück im Diesseits und darüber hinaus die ewige Glückseligkeit garantiert. ${ }^{52}$

Wie wichtig diese beiden Elemente für al-Fārābī's Staatskonzept sind, zeigt sich vollends, wenn sie in einem Gemeinwesen fehlen. Auch das kann natürlich der Fall sein, weshalb al-Fārābī nach seiner Beschreibung des Idealstaats ausführliche Betrachtungen über unvollkommene bzw. defekte Staaten anstellt. Nach seiner Darstellung können diese Defekte in zahlreichen Varianten auftreten. Deswegen diskutiert er diverse Arten von mangelhaften Gemeinwesen, die teils der historischen Realität entstammen (z.B. Tyrannis, Oligarchie oder Timokratie), teils typologischen Modellen entsprechen..$^{53}$ Letzten Endes kann man seine Enteilung jedoch auf zwei Grundtypen zurückführen, denn es gibt zwei Mängel, die grundsätzlicher Natur sind und hinter den verschiedenen Arten der Deformation stehen. Der eine ist die Unwissenheit, sowohl auf Seiten

51 Zur Sache Rosenthal 1958, 126-133; Mahdi 2001; Crone 2005, 170-187; Rudolph 2012a, 435439; vgl. auch Höffe 2016, 122-130.

52 Fārābī, Mabādi' V, 15, § 8-11; engl. Übersetzung 241-247; dt. Übersetzung 89-91; zum Vorstellungsvermögen allgemein Mabādi' IV, 14; engl. Übersetzung 211-227; dt. Übersetzung 74-82; zum Verhältnis von Philosophie und Religion Mabādi' V, 17; engl. Übersetzung 277285; dt. Übersetzung 105-109; zur Sache vgl. neben der in Anm. 51 erwähnten Literatur noch Walzer 1957.

53 Fārābī, Mabādi' VI, 18-19; engl. Übersetzung 287-329; dt. Übersetzung 110-129; zur Sache Crone 2004. 
des Herrschers als auch auf Seiten der Bürger, die laut al-Fārābī ja auf die Unterweisung durch den Philosophen- und Prophetenkönig angewiesen sind. Sie führt dazu, dass kein Mitglied des Gemeinwesens von seinem Intellekt Gebrauch macht, weshalb sämtliche Intellekte potentiell bleiben und niemals aktualisiert werden. Die Folge ist, dass alle Bürger eines solchen Staates mit dem Tod vergehen werden und niemand von ihnen Anteil an der Ewigkeit gewinnt. Der zweite Mangel entsteht dann, wenn Herrscher und Bürger zwar einen Zugang zur Wahrheit besitzen, sich aber aus Eigensucht und mangelnder Moral davon abwenden. Das führt dazu, dass ihre rationalen Seelen zwar aktualisiert sind, aber unrein werden und Schaden nehmen. Als Folge davon müssen Bürger eines solchen Staates damit rechnen, dass sie nach dem Tod fortbestehen und im Jenseits bestraft werden..$^{54}$

Al-Fārābī geht es also gar nicht darum, die Regeln der Staatskunst und der politischen Praxis auszuleuchten. Sein Ziel besteht vielmehr darin, das Nachdenken über Politik aus der Sphäre der Pragmatik herauszulösen und in einen größeren, systematischen Zusammenhang zu stellen. Politisches Denken ist für ihn kein Selbstzweck, sondern Teil eines umfassenden philosophischen Programms, das in sich kohärent ist und Anliegen der Ethik (,das Glück des Menschen“) mit solchen der Noetik (,die Aktualisierung des menschlichen Intellekts“) und der Metaphysik („die Einordnung des Menschen in die Struktur des Seins“) verbindet..5 Das alles kann man durchaus als Fortsetzung der griechischen Philosophie verstehen, doch es enthält auch Elemente, die über deren Erbe weit hinausgehen. Dazu zählen, um nur die wichtigsten nochmals zu nennen, die Bedeutung der Prophetie, das Verhältnis von Philosophie und Religion und die Rolle beider bei der Unterweisung der Menschen. Aber dazu gehört auch die Neubestimmung des Glücks, das von al-Fārābī nicht nur als klassische eudaimoneia, sondern zugleich als Glückseligkeit im Jenseits verstanden wird. ${ }^{56}$

54 Fārābī, Mabādi' V, 16; engl. Übersetzung 259-277; dt. Übersetzung 97-105.

55 Rudolph 2012a, 444-446 mit zahlreichen weiteren Literaturhinweisen.

56 Auch daran zeigt sich, dass al-Fārābī’s Überlegungen zur Politik stärker in der platonischen als in der aristotelischen Tradition stehen. Im übrigen hat die Frage, ob seine Ausführungen zu den verschiedenen politischen Gemeinschaften die Idee der Unsterblichkeit des Menschen und seines Weiterlebens im Jenseits einschließen, eine Forschungsdebatte ausgelöst; dazu ausführlich Rudolph 2012a, 440-442. 


\section{Schluss: zwischen Religion, Politik und Philosophie}

Mit diesen Eindrücken aus dem Vortrefflichen Staat kommen wir zum Abschluss unserer Betrachtungen. Sie waren eine tour d'horizon, vielleicht auch eine tour de force durch das politische Denken im frühen Islam. Aber der schnelle Durchgang durch die verschiedenen Texte und Traditionen war nötig, um einen Überblick über die Thematik zu gewinnen, was es uns jetzt ermöglicht, ein Fazit zu ziehen. Dabei böte es sich durchaus an, zahlreiche Aspekte und Details, die hier zur Sprache gekommen sind, nochmals aufzugreifen und $\mathrm{zu}$ würdigen. Im folgenden sollen aber lediglich vier Punkte herausgehoben werden, weil sie grundsätzlicher Natur sind und uns zu unserer Eingangsfrage, ob der Islam schon immer beides, also Religion und Staat gewesen sei, zurückführen. ${ }^{57}$

57 Wann genau die Formel „Der Islam ist [sc. beides:] Religion und Staat“ (al-islām dìn wadaula) aufgekommen ist, konnte noch nicht restlos geklärt werden. Die Forschung geht zur Zeit davon aus, dass sie erst Ende des 19. Jahrhunderts im Kontext des antikolonialistischen Diskurses entwickelt wurde (Bauer 2011, 342, unter Verweis auf Schulze 1982 und 21993, 115-119 sowie Krämer 1999, 43). Dazu passt, dass das arabische Wort daula erst im Kontext der modernen politischen Semantik, die zwischen Volk, Nation, Staat usw. unterscheidet, als „Staat“ im engeren Sinn verstanden wird (vgl. Nagel 1981, II 213. 223. 229-230. 234-236). - In frühislamischer Zeit wurde daula verwendet, um eine politische „Umwälzung“ oder „Revolution“ zu bezeichnen, also etwa die abbasidische Revolution von 749-750. Das legte es nahe, das Ergebnis einer solchen Umwälzung unter denselben Begriff zu fassen, weshalb unter daula bald auch eine „Dynastie“ oder allgemein „Herrschaft“ verstanden wurde. In diesem Sinne fand das Wort im 10. und 11. Jahrhundert Eingang in zahlreiche ehrende Beinamen (laqab). Herrscher verschiedenen Rangs ließen sich als 'Imād ad-Daula („Stütze der Dynastie“), Mu'izz ad-Daula (,Verherrlicher der Dynastie“) oder Saif ad-Daula (,Schwert der Dynastie“) bezeichnen. Parallel dazu kamen interessanterweise Titel mit dem Element din („Religion“) auf, so etwa Rukn ad-Dīn („Pfeiler der Religion“) oder Qawām ad-Dīn („Basis der Religion“). Sogar die Verbindung beider Elemente ist früh belegt: Um das Jahr 1000 wurde dem Kurden Hasanwaih für seine Verdienste um die Pilgerfahrten nach Mekka das Epithet Nāșir ad-Dīn wa-d-Daula („Helfer der Religion und der Dynastie“) verliehen. Das zeigt - neben dem zunehmend inflationären Gebrauch von Titeln -, dass die Begriffe din und daula keineswegs exklusiv waren, sondern in unterschiedlichen Kontexten und auf verschiedenen Ebenen der politischen Hierarchie verwendet werden konnten (zu allen hier genannten Beispielen s. Endreß 1982, 182-185). - Ein anderer semantisch interessanter Fall ist das Kitāb ad-Dīn wa-d-daula (Das Buch der Religion und der Herrschaft), das um die Mitte des 9. Jahrhunderts entstanden sein dürfte. Es stammt nach heutigem Forschungsstand von 'Alī b. Rabban aț-Ṭabarī, einem bekannten Arzt, der vom Christentum zum Islam konvertierte (Ebied/Thomas 2016, 1-24. 171-175; zur Authentizität des Textes auch Adang 2007). Nach seiner Konversion schrieb aț-Ṭabarī zwei polemische Schriften, den Radd 'alā n-Nașārā (Widerlegung der Christen) und eben das Kitāb ad-Dīn wa-d-daula, das 
Erstens: Soweit wir gesehen haben, lassen sich für die Anfänge des Islams, d. h. für die Zeit in Medina keine spezifischen politischen Konzepte erkennen. Das gilt insbesondere für den Text des Korans: Er enthält keine Aussagen über den Staat, ja nennt nicht einmal einen arabischen Begriff, mit dem der Staat bezeichnet würde. Zudem deutet er zentrale Termini wie etwa halifa noch ganz anders, als es im späteren politischen Diskurs geschehen sollte. ${ }^{58}$ Dessen ungeachtet war Mohammed natürlich der Leiter einer Gemeinde, die Beziehungen zu anderen, religiös oder tribal definierten Gemeinschaften pflegte. Außerdem hatte er das Recht, juristische Bestimmungen zu erlassen, die das Sozialleben seiner Anhänger normierten und sich zum Gesamtbild einer „guten Gewohnheit“ (sunna) formten. All das war aber nicht wirklich neu. Es entsprach vielmehr Praktiken, die bereits im alten Arabien gepflegt wurden. Und wenn Mohammed doch darüber hinaus ging, geschah das mit dem Anspruch des Propheten, eine neue Religion (dinn) bzw. eine neue Religionsgemeinschaft (umma) zu stiften, und nicht, einen Staat zu etablieren. ${ }^{59}$

in der Sekundärliteratur unter dem Titel The Book of Religion and Empire bekannt wurde. Letzteres hatte den Zweck zu beweisen, dass Mohammed entgegen den Behauptungen der Juden und Christen tatsächlich ein von Gott gesandter Prophet gewesen sei. Auch in diesem Fall geht es also nicht um politische Theorie und schon gar nicht darum, den Islam mit din und daula gleichzusetzen. Trotzdem ist der Gebrauch von din und daula in diesem Zusammenhang interessant, weil Ṭabarī offenbar zeigen wollte, dass der Erfolg Mohammeds sich sowohl im Bereich der Religion als auch im Bereich der weltlichen Herrschaft manifestiert habe.

58 Das Wort haliffa („Nachfolger“, „Stellvertreter“) wird zweimal im Koran erwähnt. In Sure 2 Vers 30 heißt es: „Damals, als dein Herr zu den Engeln sagte: ,Ich werde auf der Erde einen Nachfolger/Stellvertreter (haliffa) einsetzen', antworteten diese: ,Willst Du auf ihr jemanden [sc. vom Geschlecht der Menschen] einsetzen, der auf ihr Unheil anrichtet und Blut vergießt, während wir dir lobsingen und deine Heiligkeit preisen?` Da sprach Gott: ,Ich weiß [sc. vieles], was ihr nicht wisst.““ Und Sure 38 Vers 26 beginnt mit den Worten: „David! Wir haben dich als Nachfolger (halifa) [sc. früherer Herrscher] auf Erden eingesetzt [...].“ Keine der beiden Stellen bezieht sich also auf das Kalifenamt, das später in der Nachfolge Mohammeds eingerichtet wurde und in das Zentrum der politischen Debatte rückte. Dabei lässt sich von Sure 38 Vers 26 immerhin eine Brücke zum späteren Wortgebrauch schlagen (Nachfolge in der Herrschaft), während Sure 2 Vers 30 allgemein die Position des Menschen in der Schöpfung thematisiert (als halifa Gottes) und damit eine ganz andere Fragestellung aufwirft.

59 Vgl. etwa Sure 5 Vers 3, wo es nach einer Aufzählung ritualrechtlicher Bestimmungen heißt: „,...] Heute habe ich euch eure Religion (din) vervollständigt und meine Gnade an euch vollendet, und ich bin damit zufrieden, dass ihr den Islam als Religion habt [...].“ Oder auch Sure 5 Vers 48, wo nach der Erwähnung der Thora, des Neuen Testaments und des Korans resümiert wird: „[...] Jedem von euch [sc. Propheten] haben wir Normen und einen Weg gewiesen. Hätte es Gott beliebt, hätte er euch zu einer einzigen Glaubensgemeinschaft (umma) vereinigt. Doch will er euch im Hinblick auf das, was ihr erhalten habt, auf die Probe stellen. Darum wetteifert um das Gute! [...]“ (Übers. Nagel 1983, 170). 
Zweitens: Staatliche Strukturen und politische Konzepte im engeren Sinn werden erst unter dem Kalifat der Omayyaden erkennbar. Dabei ist es bezeichnend, dass die Omayyaden bei ihrem Versuch, politische Maximen zu entwickeln, auf antike Vorbilder zurückgreifen, was sicher nicht oder zumindest nicht in diesem Ausmaß möglich gewesen wäre, hätte es solche mit islamischer Konnotation bereits gegeben. So aber kommt es, dass um die Mitte des 8. Jahrhunderts nicht Mohammed, sondern Alexander der Große und sein Lehrer Aristoteles zu Leitsternen der politischen Reflexion werden. Damit öffnet sich das Tor zur Rezeption griechischer Ideen und Texte, die wenig später durch die Übernahme des iranischen Erbes ergänzt wird. All das geschieht nicht in dem Bewusstsein, sich fremden Einflüssen zu öffnen und dabei genuin islamische Ideen aufzugeben. Im Gegenteil: Das Kalifen verstehen sich nicht als Zerstörer, sondern - im Sinne der translatio imperii - als Vollender der Reiche und der Kulturen, deren Erbe sie antreten. ${ }^{60}$

Drittens: So entstehen mehrere Linien des Nachdenkens über Politik, die wir durch Texte von al-Māwardī, Niẓām al-Mulk und al-Fārābī kennen gelernt haben. ${ }^{61}$ Sie alle entwickeln auch Vorstellungen zur Frage der Religion, wobei ihre Perspektiven und Zielsetzungen jeweils unterschiedlich sind. Al-Māwardī versteht die Religion vor allem als Kontrollinstanz. Nach seiner Auffassung sollten sämtliche Abläufe bei der Lenkung und der Verwaltung des Gemeinwesens den Erfordernissen der Scharia entsprechen. Letztere kann aber, wie wir

60 Zur translatio imperii und dem komplementären Konzept der translatio scientiae bzw. translatio studii s. Rudolph 2011, 282-284. 300-301.

61 In seiner Übersicht über das politische Denken der Muslime listet Bauer 2011, 321-322 neben den drei Diskurstraditionen, die hier näher besprochen worden sind, noch drei weitere auf: (a) den panegyrischen Diskurs der Dichter, (b) den Diskurs der Theologen und (c) den Diskurs der Historiker. Dabei sind vor allem seine Ausführungen zu (a) von großem Interesse, die an einem Beispiel aus dem 14. Jahrhundert belegen, dass es eine anhaltende Tradition der säkularen politischen Dichtung gegeben hat (meist in der Form von Herrscherlob), die in der Forschung zu Unrecht vernachlässigt worden ist (Bauer 2011, 325-331). Die beiden anderen von ihm identifizierten Diskurstraditionen können allerdings keine vergleichbare Bedeutung für sich in Anspruch nehmen. Der theologische Diskurs (b) bildete gemeinsam mit dem juristischen (der hier am Text von Māwardī exemplifiziert worden ist) das religiöse Feld, das sich grundsätzlich auf das Vorbild Mohammeds berief; dabei traten die theologischen Aspekte gegenüber den juristischen zunehmend in den Hintergrund, wie Bauer 2011, 311 selbst betont. Der Diskurs der Historiographen (c) enthält sicher interessante Details, hat aber erst spät genau genommen mit Ibn Haldūn (gest. 1406) - eine eigenständige theoretische Basis gefunden. Die ältere Geschichtsschreibung bewegte sich durchweg in dem konzeptuellen Rahmen, der hier mit den drei Traditionslinien (also dem arabisch-islamischen, dem persischen und dem griechischen Modell) skizziert wurde; vgl. etwa zur islamischen Universalgeschichte und deren Verhältnis zur Antike Rudolph 2011, 280-288. 
am Beispiel der „Herrschaft durch Usurpation“ gesehen haben, durchaus flexibel gehandhabt werden, sollten es die politischen und gesellschaftlichen Umstände erfordern. Niz̄ām al-Mulk legt den Akzent eher auf die Seite der Politik. Da sie mit Klugheit und größtmöglicher Umsicht ausgeführt werden sollte, setzt Gott in jeder Epoche einen geeigneten Herrscher ein, um die Geschicke der Welt zu leiten. Ihm obliegt es dann auch, die richtige Religion zu unterstützen und in seinem Reich durchzusetzen, womit der Primat der Politik noch sichtbarer wird. Al-Fārābī schließlich setzt weder den Staat noch die Religion absolut. Beide haben vielmehr eine dienende Funktion in dem Prozess, die Menschen zur Erlangung des Glücks anzuleiten. Sowohl die Religion als auch die Politik stehen im Vortrefflichen Staat also im Dienst einer Ethik, deren Prinzipien und Perspektiven philosophisch konzipiert sind. Letzteres hat bei manchen Betrachtern den Verdacht aufkommen lassen, al-Fārābī habe sich vom Islam distanziert. Deswegen wurde ihm in der Forschung gelegentlich unterstellt, seine Aussagen zu Metaphysik und Religion hätten funktionalen Charakter und entsprächen nicht seinen tatsächlichen Überzeugungen. ${ }^{62}$ Dagegen sprechen aber gute Gründe, ${ }^{63}$ zumal gerade sein Werk über den Vortrefflichen Staat, mit dem wir uns hier befasst haben, zentrale Anliegen der islamischen Theologie aufnimmt. ${ }^{64}$

Viertens und letztens: Dass al-Fārābī von seiner Umgebung als islamischer Autor wahrgenommen wurde, belegt auch die Rezeption, die ihm später zuteil wurde. Sie war markant und hielt über Jahrhunderte an, was im übrigen auf alle drei Schriften, die wir gerade besprochen haben, zutrifft. Al-Māwardī's Werk Die Bestimmungen der Herrschaft wurde von zahllosen islamischen Juristen gelesen und kommentiert. Niẓām al-Mulk’s Buch der Regierungskunst wurde - neben anderen Fürstenspiegeln - noch im Osmanischen Reich hoch geschätzt und vielfach studiert. ${ }^{65}$ Die ungewöhnlichste Rezeptionsgeschichte erlebte indes alFārābī's Vortrefflicher Staat. Dabei spielte ein persischer Gelehrter des 13. Jahrhunderts namens Nașīr ad-Dīn aț-Ṭūsī (1201-1274) eine große Rolle. Er verfasste nämlich die Ethik für [sc. den Emir] Nāṣir (Ahlāq-i Nāṣirī), eine umfassende Darlegung zur ethischen, ökonomischen und politischen Fragen, in der er sehr stark auf al-Fārābī’s Ideen zurückgriff. ${ }^{66}$ Ṭūsī’s Schrift fand ihrerseits ein breites und lang anhaltendes Echo, was sich an drei Beispielen illustrieren lässt. Im 15.

62 Vgl. z.B. Parens 1995 und Colmo 338.

63 Dazu ausführlich Rudolph 2012a, 432-433.

64 Rudolph 2009.

65 Aksan 1993, 53; Hagen 2012, 434.

66 Der Text ist zugänglich in einer vollständigen engl. Übersetzung von Wickens 1964 (s. unten aț-Ṭūsī im Literaturverzeichnis); zu Ṭūsī’s Leben und Wirken Rizvi 2013b; zu Inhalt und Einordnung der Schrift Madelung 1985. 
Jahrhundert nutzte der Iraner Ǧalāl ad-Dīn ad-Dawānī (1427-1502) den Text, um seine eigene Ethik von Ğalāl [sc. ad-Dīn] (Ahllāq-i Ğalālī) zu schreiben - wieder unter Einschluss farabianischer und platonischer Ideen zur Politik. ${ }^{67} \mathrm{Im} 16$. Jahrhundert tat es der osmanische Denker 'Alī Kınalızāde (1510-1572) ihm gleich. So entstand die Ethik von 'Alä' [sc. ad-Dīn] (Ahlāq-i 'Alā'î), in der Kınalizāde übrigens seinen Lesern erklärte, die gerechte und vortreffliche Herrschaft, die schon Platon empfohlen habe, sei nun endlich vom osmanischen Sultan Süleyman (dem Prächtigen) in die Tat umgesetzt worden. ${ }^{68} \mathrm{Im}$ 19. Jahrhundert kamen schließlich britische Kolonialbeamte in Indien auf die Idee, Dawān̄’s Schrift ins Englische zu übertragen und im Schulunterricht über ethische und politische Fragen einzusetzen. ${ }^{69}$ Ob diese Lektüre den Schülern gefallen hat, wissen wir nicht. Aber es zeigt doch, dass sich gute Konzepte immer wieder durchsetzen und dass die politische Philosophie, die einst Platon und auf ihm aufbauend al-Fārābī entworfen hatten, in der islamischen Welt noch immer in hohem Ansehen stand.

\section{Literaturverzeichnis}

\section{Primärliteratur}

[Ardaschir:] 'Ahd Ardašīr, ed. Iṇsān 'Abbās, Beirut 1967.

Ps.-Aristoteles: Sirr al-asrār, ed. 'Abdarraḥmān Badawī, in: al-Ușūl al-yunāniyya li-l-naẓariyyāt as-siyāsiyya fí l-Islām. Kairo 1954, 65-171, sowie: ed. Sāmī Salmān al-A'war, 2. Aufl., Beirut 1986.

ad-Dawānī, Ǧalāl ad-Dīn: Aḥlāq-i Ǧalālī, engl. Übersetzung von W.F. Thompson: Practical Philosophy of the Muhammadan People, exhibited in its professed connexion with the European, so as to render either an introduction to the other, being a translation of the Akhläk-i-Jaläly, the most esteemed ethical work of Middle Asia, London 1839.

67 Zu Dawānī’s Leben und Wirken Rizvi 2013a; eine Analyse des Werks gibt Rosenthal 1958, 210-233.

68 Hagen 2012, 433-438; vgl. Aksan 1993, 53-54; Darling 2013, 402 (mit dem Hinweis auf Platon).

69 So entstand die Übersetzung von Thompson 1839 (s. unten ad-Dawānī im Literaturverzeichnis). 
al-Fārābī, Abū Nașr: Mabādi' ārā' ahl al-madīna al-fāḍila, ed. u. engl. Übersetzung von Richard Walzer: Al-Farabi on the Perfect State, Oxford 1985 (Nachdruck 1998). - Dt. Übersetzung von Cleophea Ferrari: Die Prinzipien der Ansichten der Bewohner der vortrefflichen Stadt, Stuttgart 2009. - Ed. und franz. Überstzung von Amor Cherni: Opinions des habitants de la cité vertueuse, Beirut 2011.

Ps.-Ǧāḥiẓ: Kitāb at-Tāğ fĩ ahlāa al-mulūk, ed. Aḥmad Zakī Bāšā. Kairo 1914. - Franz. Übersetzung von Charles Pellat: Le livre de la couronne, Paris 1954.

Ibn al-Muqaffa': Kitāb al-Adab al-kabīr, ed. Muhammad Farīd Kurd 'Alī, in: Rasāill al-bulaḡā', Kairo 1954, sowie: Al-Adab al-kabīr wa-l-adab aș-șagīrr, Beirut 1956, sowie: Beirut 2001.

Ibn al- Muqaffa': Risāla fi ș-șaḥāba, ed. u. franz. Übersetzung von Charles Pellat: Ibn al-Muqaffa. „Conseilleur“ du Calife, Paris 1976.

al-Māwardī, Abū l-Ḥasan: al-Aḥkām as-sulțāniyya wa-l-wilāyāt ad-dīniyya, ed. Max Enger, Bonn 1853, sowie: Kairo ${ }^{3} 1973$, sowie: Beirut 1983. - Franz. Übersetzung von E. Fagnan: Mawerdi. Les statuts gouvernementaux ou règles de droit public et administratif, Alger 1915. - Engl. Übersetzung von Wafaa Hasan Wahba: The Ordinances of Government, Reading 1996, sowie von: Asadullah Yate: The Laws of Islamic Governance, London 2005.

Niẓām al-Mulk: Siyāsatnāma, ed. Charles Schefer, Paris 1891, sowie: ed. 'Abdurraḥīm-i Halhāāī, Teheran 1931, sowie: ed. Hubert Darke, Teheran 1968, sowie: ed. Mehmet Altay Köymen, Ankara 1999. - Franz. Übersetzung von Charles Schefer: Siasset Namèh. Traité de gouvernement, Paris 1893. - Engl. Übersetzung von Hubert Darke: The Book of Government or Rules for Kings, London 1960 (Nachdrucke 1978 u. 2002). Dt. Übersetzung von Karl Emil Schabinger von Schowingen: Das Buch der Staatskunst. Siyāsatnāma: Gedanken und Geschichten, Freiburg, München 1960; Neuausgabe von Karl Friedrich Schabinger von Schowingen, Zürich 1987 (danach hier zitiert).

[Tansar:] The Letter of Tansar, translated by Mary Boyce, Roma 1968.

aț-Ṭūsī, Nașīr ad-Dīn: Ahlāq-i Nāșirī, engl. Übersetzung von G.M. Wickens: The Nasirean Ethics by Nașir al-Dīn Ṭūsī, London 1964.

\section{Sekundärliteratur}

Adang 2007: Camilla Adang, „A Rare Case of Biblical „Testimonies“ to the Prophet Muhammad in Mu'tazilī Literature. Quotations from Ibn Rabban al-Tabarī’s Kitāb al-dīn wa-ldaula in Abū l-Ḥusayn al-Bașrī’s Ghurar al-adilla, as Preserved in a Work by alḤimmașī al-Rāzī“, in: Camilla Adang, Sabine Schmidtke and David Sklare (eds.), $A$ Common Rationality. Mu'tazilism in Islam and Judaism, Würzburg, 297-330. 
Akhavi 2011: Shahrough Akhavi, „The Muslim Tradition of Political Philosophy“, in: George Klosko (ed.), The Oxford Handbook of the History of Political Philosophy, Oxford, 789-802.

Akpinar 2013: Mehmetcan Akpinar, „Mawardi (974-1058)“, in: Böwering 2013a, 331-332. Amirpur 2009: Katajun Amirpur (ed.), Hasan Yusuf Eshkevari, Mohsen Kadivar, Mohammed Mojtahed Shabestari: Unterwegs zu einem anderen Islam. Texte iranischer Denker, Freiburg i. Br.

Amirpur 2013: Katajun Amirpur, Den Islam neu denken. Der Dschihad für Demokratie, Freiheit und Frauenrechte, München.

Bauer 2011: Thomas Bauer, Die Kultur der Ambiguität. Eine andere Geschichte des Islams, Berlin.

Bobzin 2000: Hartmut Bobzin, Mohammed, München (5. Aufl. 2016).

Böwering 2013a: Gerhard Böwering (ed.), The Princeton Encyclopedia of Islamic Political

Thought, Princeton.

Böwering 2013b: Gerhard Böwering, „Qur’an“, in: Böwering 2013a, 447-456.

Brague 1993: Rémi Brague, „Note sur la tradition arabe de la politique, derechef qu'elle n'existe pas“, in: Pierre Aubenque (éd.), Aristote politique, Paris, 423-433.

Calvert 2010: John Calvert, Sayyid Qutb and the Origins of Radical Islamism, New York.

Colmo 2005: Christopher Colmo, Breaking with Athens. Alfarabi as Founder, Lanham.

Crone 2004: Patricia Crone, „Al-Fārābī’s Imperfect Constitutions“, Mélanges de l'Université Saint-Joseph 57, 191-228.

Crone 2005: Patricia Crone, Medieval Islamic Political Thought, Edinburgh [leicht überarbeitete Paperbackversion der Originalausgabe Edinburgh 2004, die auch erschienen ist unter dem Titel: God's Rule. Government and Islam. Six Centuries of Medieval Islamic Political Thought, New York 2004].

Crone/Hinds 1986: Patricia Crone and Martin Hinds, God's Caliph. Religious Authority in the First Centuries of Islam, Cambridge.

Damir-Geilsdorf 2003: Sabine Damir-Geilsdorf, Herrschaft und Gesellschaft. Der islamistische Wegbereiter Sayyid Quțb und seine Rezeption, Würzburg.

Darling 2013: Linda T. Darling, „Ottomans (1299-1924)“, in: Böwering 2013a, 402-403.

De Smet 2011: Daniel De Smet, „L'héritage de Platon et de Pythagore: la „voie diffuse“ de sa transmission en terre d'Islam“, in: Richard Goulet et Ulrich Rudolph (éds.), Entre Orient et Occident: la philosophie et la science gréco-romaines dans le monde arabe (Entretiens sur l'Antiquité Classique de la Fondation Hardt 57), Vandœuvres-Genève, 87-133.

Denny 1977: Frederick Mathewson Denny, „Ummah in the Constitution of Medina“, Journal of Near Eastern Studies 36, 39-47. - Nachdruck in: Saeed 2011, vol. I, 83-93 (danach hier zitiert). 
Denny 2001: Frederick Mathewson Denny, „Community and Society in the Qur’ān“, in: Jane Dammen McAuliffe (ed.), Encyclopaedia of the Qur'ān, Leiden, Boston, vol. I, 367386.

Ebied/Thomas 2016: Rifaat Ebied and David Thomas (eds.), The Polemical Works of 'Alī al-Ṭabarī, Leiden, Boston.

Emon 2001: Anver Emon, „Reflections on the „Constitution of Medina“. An Essay on Methodology and Ideology in Islamic Legal History“, UCLA Journal of Islamic and Near Eastern Law 1, 103-133. - Nachdruck in: Saeed 2011, vol. I, 55-82 (danach hier zitiert).

Endreß 1982: Gerhard Endreß, Einführung in die islamische Geschichte, München (3. Aufl. 1997).

van Ess 1991-1997: Josef van Ess, Theologie und Gesellschaft im 2. und 3. Jahrhundert

Hidschra. Eine Geschichte des religiösen Denkens im frühen Islam, Berlin, New York, Bände I-VI.

Forster 2006: Regula Forster, Das Geheimnis der Geheimnisse. Die arabischen und deutschen Fassungen des pseudo-aristotelischen Sirr al-asrār / Secretum secretorum, Wiesbaden.

Goitein 1949: Shlomo Dov Goitein, „A Turning Point in the History of the Muslim State (Apropos of Ibn al-Muqaffa“'s Kitāb al-Ṣaḥāba)“, Islamic Culture 23, 120-135 (Nachdruck in: Shlomo Dov Goitein, Studies in Islamic History and Institutions, Leiden 1966, 149167).

Goldziher 1902: Ignaz Goldziher, „Neutestamentliche Elemente in der Traditionslitteratur des Islam“, Oriens Christianus 2, 390-397 (Nachdruck in: Ignaz Goldziher, Gesammelte Schriften, Hildesheim 1970, Bd. IV, 315-322).

Goldziher 1908: Ignaz Goldziher, „Neuplatonische und gnostische Elemente im Ḥadīt““, Zeitschrift für Assyriologie und verwandte Gebiete 22, 317-344 (Nachdruck in: Ignaz Goldziher, Gesammelte Schriften, Hildesheim 1970, Bd. V, 107-134.)

Grignaschi 1966: Mario Grignaschi, „Quelques spécimens de la littérature sassanide conservés dans les bibliothèques d'Istanbul“, Journal Asiatique 254, 1-142.

Günther 2014: Christoph Günther, Ein zweiter Staat im Zweistromland? Genese und Ideologie des „Islamischen Staates Irak“, Würzburg.

Gutas 1998: Dimitri Gutas, Greek Thought, Arabic Culture. The Graeco-Arabic Translation Movement in Baghdad and Early 'Abbāsid Society ( $2^{\text {nd }}-4^{\text {th }} / 8^{\text {th }}-10^{\text {th }}$ centuries), London, New York.

Gutas 2012a: Dimitri Gutas, „Die Wiedergeburt der Philosophie und die Übersetzungen ins Arabische“, in: Ulrich Rudolph (Hg.), Philosophie in der islamischen Welt, I: 8.-10. Jahrhundert, Basel, 55-91.

Gutas 2012b: Dimitri Gutas, „Populäre Ethik und praktische Politik“, in: Ulrich Rudolph (Hg.), Philosophie in der islamischen Welt, I: 8. -10. Jahrhundert, Basel, 458-475; 540542. 
Hagen 2012: Gottfried Hagen, „The Order of Knowledge, the Knowledge of Order: Intellectual Life“, in: Suraiya Faroqhi and Kate Fleet (eds.), The Cambridge History of Turkey, II: The Ottoman Empire as a World Power, Cambridge, 407-456.

Haghighat 2015: Seyed Sadegh Haghighat, „Persian Mirrors for Princes: Pre-Islamic and Islamic Mirrors Compared“, in: Regula Forster and Neguin Yavari (eds.), Global Medieval. Mirrors for Princes Reconsidered, Boston u.a., 83-93.

Hamid 2001: Eltigani Abdulqahir Hamid, „Al-Māwardī’s Theory of State. Some Ignored Dimensions“, American Journal of Islamic Social Sciences 18,4, 1-18. - Nachdruck in: Saeed 2011, vol. I, 221-234 (danach hier zitiert).

Hamori 2013: Andreas Hamori, „Ibn al-Muqaffa' (ca. 720-756)“, in: Böwering 2013a, 232-233. Höffe 2016: Otfried Höffe, Geschichte des politischen Denkens, München.

Horst 1987: Heribert Horst, „Die Entstehung der adab-Literatur und ihre Arten“, in: Helmut Gätje (Hg.), Grundriss der Arabischen Philologie, II: Literaturwissenschaft, Wiesbaden, 208-220.

Juynboll 1983: Gautier H. A. Juynboll, Muslim Tradition, Cambridge.

Kadivar 2017: Mohsen Kadivar, Gottes Recht und Menschenrechte. Eine Kritik am historischen Islam, übers. und mit einer Einleitung von Armin Eschraghi, Freiburg i. Br.

Khatab 2006: Sayed Khatab, The Power of Sovereignty. The Political and Ideological Philosophy of Sayyid Qutb, London.

Krämer 1999: Gudrun Krämer, Gottes Staat als Republik. Reflexionen zeitgenössischer Muslime zu Islam, Menschenrechten und Demokratie, Baden-Baden.

Krämer 2010: Gudrun Krämer, Hasan al-Banna, Oxford.

Lambton 1981: Ann K.S. Lambton, State and Government in Medieval Islam. An Introduction to the Study of Islamic Political Theory: the Jurists, Oxford.

Lambton 1984: Ann K.S. Lambton, „The Dilemma of Government in Islamic Persia. The Siyāsatnāma of Niẓām al-Mulk“, Iran 22, 55-66. - Nachdruck in: Saeed 2011, vol. II, 3-21 (danach hier zitiert).

Latham 1997: J. Derek Latham, Art. „Ebn al-Moqaffa““, Encyclopaedia Iranica, VIII, 39-41.

Lecker 2013: Michael Lecker, „Constitution of Medina“, in: Böwering 2013a, 115-116.

Little 1974: Donald P. Little, „A New Look at al-Ahkām al-sulțāniyya“, The Muslim World 64, 115. - Nachdruck in: Saeed 2011, vol. I, 235-247 (danach hier zitiert).

Madelung 1985: Wilferd Madelung, „Nașīr al-Dīn al-Ṭūsī's Ethics between Philosophy, Shi'ism, and Sufism“, in: Richard G. Hovannisian (ed.), Ethics in Islam, Malibu, 85-101.

Mahdi 2001: Muhsin Mahdi, Alfarabi and the Foundation of Islamic Political Philosophy, Chicago, London.

Meddeb 2007: Abdelwahab Meddeb, Die Krankheit des Islam, Zürich (franz. Original: La maladie de l'Islam, Paris 2002).

Motzki 2004: Harald Motzki (ed.), Hadith. Origins and Developments, Aldershot.

Motzki 2014: Harald Motzki, Wie glaubwürdig sind Hadithe? Die klassische islamische HadithKritik im Licht moderner Wissenschaft, Wiesbaden. 
Nagel 1981: Tilman Nagel, Staat und Glaubensgemeinschaft im Islam. Geschichte der politischen Ordnungsvorstellungen der Muslime, Bände I-II, Zürich.

Nagel 1983: Tilman Nagel, Der Koran. Einführung, Texte, Erläuterungen, München (4. Aufl. 2002).

Parens 1995: Joshua Parens, Metaphysics as Rhetoric. Alfarabi's Summary of Plato's „Laws“, Albany.

Pines 1986: Shlomo Pines, „Aristotle’s Politics in Arabic Philosophy“, in: Ders. (ed.), Studies in Arabic Versions of Greek Texts and in Mediaeval Science (The Collected Works of Shlomo Pines, II), Jerusalem, Leiden, 146-156.

Rizvi 2013a: Sajjad H. Rizvi, „Dawani, Jalal al-Din (1427-1502)“, in: Böwering 2013a, 126. Rizvi 2013b: Sajjad H. Rizvi, „al-Tusi, Nasir al-Din (1201-1274)“, in: Böwering 2013a, 570-571. Rosenthal 1958: Erwin I. J. Rosenthal, Political Thought in Medieval Islam. An Introductory Outline, Westport CT (zahlreiche Nachdrucke).

Rudolph 2009: Ulrich Rudolph, „Reflections on al-Fārābī’s Mabādi' ärā' ahl al-madīna alfạ̈̂ila“, in: Peter Adamson (ed.), In the Age of al-Fārābī. Arabic Philosophy in the Fourth/Tenth Century, London, 1-14.

Rudolph 2011: Ulrich Rudolph, „Die Deutung des Erbes. Die Geschichte der antiken Philosophie und Wissenschaft aus der Sicht arabischer Autoren“, in: Richard Goulet et Ulrich Rudolph (éds.), Entre Orient et Occident: la philosophie et la science gréco-romaines dans le monde arabe (Entretiens sur l'Antiquité Classique de la Fondation Hardt 57), Vandœuvres-Genève, 279-320.

Rudolph 2012a: Ulrich Rudolph, „Abū Nașr al-Fārābī“, in: Rudolph 2012b, 363-457.

Rudolph 2012b: Ulrich Rudolph (Hg. unter Mitarbeit von Renate Würsch), Philosophie in der islamischen Welt, I: 8.-10. Jahrhundert (Grundriss der Geschichte der Philosophie, begründet von Friedrich Ueberweg, völlig neu bearbeitete Ausgabe), Basel.

Rudolph/Uehlinger 2014: Ulrich Rudolph u. Christoph Uehlinger, „Positionen aktueller Mohammed-Forschung“, Asiatische Studien, 68, 433-437.

Ryan/Schmitt 1982: William Francis Ryan and Charles B. Schmitt (eds.), Pseudo-Aristotle. The Secret of Secrets. Sources and Influences, London.

Saeed 2011: Abdullah Saeed, Islamic Political Thought and Governance. Critical Concepts in Political Science, vols. I-IV, London, New York.

Schöller 2008: Marco Schöller, Mohammed, Frankfurt a. M.

Schulze 1982: Reinhard Schulze, „Die Politisierung des Islam im 19. Jahrhundert“, Welt des Islams 22, 105-116.

Schulze 1993: Reinhard Schulze, „Islam und Herrschaft. Zur politischen Instrumentalisierung einer Religion“, in: Michael Lüders (Hg.), Der Islam im Aufbruch? Perspektiven der arabischen Welt, 2. Aufl., München, Zürich, 94-129.

Sievert 2015: Henning Sievert, „Der Schutzvertrag von Raqqa und die Verlautbarung von Mosul. Ein Beitrag zur Diskussion über den ,Islamischen Staat im Irak und in Syrien““, Asiatische Studien 69, 73-98. 
Sing 2007: Manfred Sing, Progressiver Islam in Theorie und Praxis. Die interne Kritik am hegemonialen Diskurs durch den „roten Scheich“ 'Abdallāh al-'Alāyilī (1914-1996), Würzburg.

Walzer 1957: Richard Walzer, „Al-Fārābī’s Theory of Prophecy and Divination“, Journal of Hellenic Studies 77, 142-148.

Watt 1968: W. Montgomery Watt, Islamic Political Thought. The Basic Concepts, Edinburgh (zahlreiche Nachdrucke).

Yavari 2013: Neguin Yavari, „Nizam al-Mulk (1018-92)“, in: Böwering 2013a, 392-393.

Zakeri 2015: Mohsen Zakeri, „A Proposal for the Classification of Political Literature in Arabic and in Persian. Folk Narrative as a Source of Political Thought?“, in: Regula Forster and Neguin Yavari (eds.), Global Medieval. Mirrors for Princes Reconsidered, Boston u.a., 174-197. 